\title{
Latin American View of the Radiographic Study of Ankle Fractures Type A0 44-B1 e B2
}

\author{
Labronici, Pedro José ${ }^{1}$, Fogagnolo Fabricio ${ }^{2}$, Belangero William Dias ${ }^{3}$ and Amorim Luiz \\ Eduardo $^{4 *}$ \\ ${ }^{1}$ Professor at Petrópolis Medical School and at Fluminense Federal University, Brazil
}

${ }^{2}$ Professor at Ribeirão Preto University, Brazil

${ }^{3}$ Professor at Campinas University, Brazil

${ }^{4}$ Professor at Rio de Janeiro Federal University, Brazil

*Corresponding author: Amorim Luiz Eduardo, Professor at Rio de Janeiro Federal University, Brazil

\begin{abstract}
ARTICLE INFO
Received: 幽 February 11, 2021

Published: 幽 February 17, 2021

Citation: Labronici, Pedro José, Fogagnolo Fabricio, Belangero William Dias, Amorim Luiz Eduardo. Latin American View of the Radiographic Study of Ankle Fractures Type AO 44-B1 e B2. Biomed J Sci \& Tech Res 34(1)-2021. BJSTR. MS.ID.005484.
\end{abstract}

Keywords: Ankle Fracture; Radiographies; Supination-External Rotation

\section{ABSTRACT}

Objective: to assess whether there is a type of image that guides the surgeon to indicate surgical treatment for ankle fractures and to determine whether the surgeon's decision is associated with the age and experience of the evaluator, considering surgeons of different nationalities. Material and Methods: Three different presentations of radiographic images of ankle fractures were analyzed in 36 patients, in anteroposterior and lateral view, true anteroposterior and lateral view, and the three images combined. The images were evaluated randomly and independently by 89 professionals of different nationalities, ages, and lengths of experience. Results: For professionals from Ecuador, Argentina, Mexico, and Chile, the indications for surgery are more frequent when the images are presented in true anteroposterior and lateral view. For professionals from Peru, Venezuela, Bolivia, Paraguay, Brazil, Colombia, Uruguay, and Guatemala, as in the overall assessments, the indications for surgery are more frequent when images of the three positions combined are presented.

In all countries and in general, there are lower frequencies of indications for surgery when the image is presented only in the anteroposterior and lateral view. In only five of the 108 assessments (4.6\% of the assessments) was there a significant association of the surgical decision in relation to the length of medical experience of the evaluating physician. Conclusion: In most of the countries, indications for surgery are more frequent when images of the three positions combined are presented. However, the highest frequencies of indicated surgery were observed when the image was presented only in the true anteroposterior and lateral view. The surgical indications are not associated with the length of medical experience of the evaluating physician.

\section{Introduction}

Ankle fractures are among the most frequent injuries of the musculoskeletal system and correspond to approximately $9 \%$ of all fractures 1 and account for $10 \%$ of all $\mathrm{x}$-rays performed on patients in emergency departments, resulting in a significant expense [18]. In ankle fractures, radiographic assessment is essential. The Ottawa ankle rules represented an attempt to reduce the indication of study by radiographs. However, the low radiation dose and the low cost of $x$-ray are much less important than the possibility of failure in diagnosis [6]. The exam with conventional radiographs for the diagnosis of ankle fractures consists of anteroposterior, anteroposterior with $20^{\circ}$ internal rotation (true), and lateral images. Various studies have contested the need for three radiographic images for the diagnosis of ankle fractures $[2,4,9,10]$. Countless authors have suggested that two images can replace the three images without affecting patient results $[2,4,9,11,12]$. Some studies suggest that anteroposterior and lateral images could be used for the diagnosis of fractures [2,10]. However, when using two images, various authors recommend doing the anteroposterior with $20^{\circ}$ internal rotation (true) and lateral image as they would provide, "with 95\% accuracy", diagnosis of ankle fractures, when 
compared to the series of three views [4,9]. In most of these studies, the combination of two images was tested, comparing the standard series of three images, selected based on the researcher's preference (anteroposterior or true anteroposterior) [11] compared the images for the diagnosis of ankle fractures and combined the individual results to compare the performance between two and three images. This study aims to assess whether there is a type of image that guides the surgeon to indicate surgical treatment for ankle fractures and to determine whether the surgeon's decision is associated with the age and experience of the evaluator, considering surgeons of different nationalities.

\section{Material and Methods}

This cross-sectional observational study was carried out between March 1 and June 30, 2019, involving 89 professional evaluators and 36 patients with ankle fractures treated in a tertiary hospital. The inclusion criteria were patients over 18 years old, diagnosed with supination external rotation type 44-B1 or B2 ankle fracture who had radiographs in three projections during the study period. Exclusion criteria were patients with open fractures, old fractures of the ankle, or fractures due to metabolic or tumor alterations. The inclusion criteria for the evaluators were physicians trained with more than one year in orthopedics and traumatology. The evaluator exclusion criteria were physicians who did not work with traumatology. The study was approved by the Research Ethics Committee under registration CAAE 05677819.4.0000.9007. To fulfill the objective of the study, three different presentations of radiographic images of ankles of 36 patients were randomly and independently evaluated by 89 professionals of different nationalities, ages, and time since graduation. Each of the 36 cases was presented to the evaluators as follows:

a) Presentation 1: radiographic image of the ankle in anteroposterior and lateral view.

b) Presentation 2: radiographic image of the ankle in an anteroposterior position with an internal rotation of $20^{\circ}$ (mortise view) and lateral view.

c) Presentation 3: radiographic image of the ankle with the three images combined (anteroposterior, mortise, and lateral view). The 108 presentations were provided to the evaluators in random order and independently, on a digital platform, under the control of the researchers only. For each presentation, the evaluators indicated their decision for surgical or conservative treatment. Once the result was indicated by the evaluator for the type of treatment, the program did not allow them to return later to change the indication. This was decided so that evaluators did not change their opinion when they identified the case in the presentations with three images.

\section{Statistical Analysis Methodology}

The evaluators' data (age, time since graduation, and country of practice), and their responses for surgical indication in each of the 108 assessments were automatically placed in a Microsoft Excel 2013 spreadsheet, thus building the research database. Other statistical analyses were conducted using the IBM SPSS program (Statistical Package for the Social Sciences), version 22.0. The quantitative variables age and time since graduation were described by the minimum, maximum, mean, median, standard deviation, and coefficient of variation (CV) statistics. The variability in the distribution of a quantitative variable was considered low if $\mathrm{CV}<0.20$; moderate if $0.20 \leq \mathrm{CV}<0.40$ and high if $\mathrm{CV} \geq 0.40$. For each of the three types of case presentation, the results of the outcome of interest (surgical indications) were presented in tables and graphs by absolute frequency and percentage (relative rate of surgical indication). To compare the age and time since graduation of the professionals who did indicate and who did not indicate surgery, the Mann-Whitney test was used, since the distribution of these variables was not normal in the data from this study.

The normality of the distribution of the age variable and the time since graduation variable was investigated using the ShapiroWilk test. Due to the non-normality of the distribution of the variables, the correlation between the quantitative variables was investigated using Spearman's rank-order correlation coefficient, with significance analysis of the correlation coefficient made through the correlation coefficient significance test. All discussions were conducted at the maximum significance level of $5 \%(0.05)$.

\section{Results}

\section{Professionals' Profile}

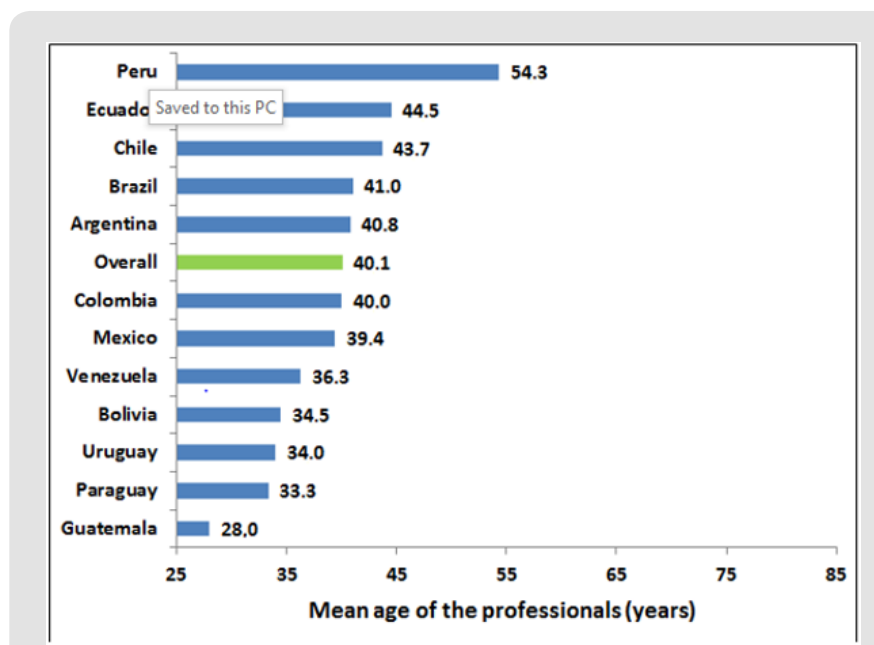

Figure 1: Mean age of the professionals in descending order, by country.

Table 1 shows the frequency distribution of the country where the evaluators work and the main statistics on the age of the professionals, by country and overall. The sample contains professionals from 12 countries in South, Central, and North America, with Brazil and Mexico being the countries with the largest representation in the sample, $33.7 \%$ and $15.7 \%$ respectively. Overall, the evaluators who participated in this study ranged in age 
from 27 to 82 years, with a mean of 40.1 years, median of 38.0 years, standard deviation of 10 years, resulting in a coefficient of variation of 0.25 , which shows moderate variability in the age distribution of these professionals. The graph in Figure 1 shows the mean age of the professionals in descending order by country. In terms of means, the countries Peru, Ecuador, Chile, and Brazil had the oldest evaluators, with mean ages over 40 years, while Guatemala had a 28-year-old professional.

Table 1: Frequency distribution of the country in which the evaluators practice and the main statistics on the time since they graduated, by country and overall.

\begin{tabular}{|c|c|c|c|c|c|c|c|}
\hline \multirow{2}{*}{ Country of practice } & \multirow{2}{*}{ Number of Cases } & \multicolumn{6}{|c|}{ Time since Graduation of The Professionals } \\
\hline & & Minimum & Maximum & Mean & Median & Standard Deviation & Coefficient of Variation \\
\hline Argentina & 8 & 3 & 29 & 13 & 12 & 9 & 0.69 \\
\hline Bolivia & 2 & 2 & 5 & 3.5 & 4 & 2.1 & 0.61 \\
\hline Brazil & 30 & 2 & 34 & 13.1 & 13 & 9 & 0.69 \\
\hline Chile & 3 & 4 & 39 & 16 & 5 & 19.9 & 1.25 \\
\hline Colombia & 9 & 2 & 22 & 8.8 & 6 & 7.3 & 0.83 \\
\hline Ecuador & 2 & 10 & 15 & 12.5 & 13 & 3.5 & 0.28 \\
\hline Guatemala & 1 & 2 & 2 & 2 & 2 & - & - \\
\hline Mexico & 14 & 2 & 33 & 11.8 & 9 & 10 & 0.85 \\
\hline Paraguay & 3 & 1 & 12 & 5 & 2 & 6.1 & 1.22 \\
\hline Peru & 4 & 4 & 50 & 21.3 & 16 & 21.1 & 0.99 \\
\hline Uruguay & 1 & 5 & 5 & 5 & 5 & - & - \\
\hline Venezuela & 12 & 3 & 28 & 7.8 & 6 & 6.7 & 0.86 \\
\hline Overall & 89 & 1 & 50 & 11.5 & 7 & 9.8 & 0.85 \\
\hline
\end{tabular}

Table 2 shows the frequency distribution of the country in which the evaluators practice and the main statistics on the time since they graduated, by country and for the overall sample. Overall, the physicians who participated in this study had their time since graduation varying from 1 to 50 years, with a mean of 11.5 years, median of 7.0 years, standard deviation of 9.8 years, resulting in a coefficient of variation of 0.85 , which shows high variability in the distribution of time since graduation for these professionals.
The graph in Figure 2 shows the means for time since graduation of the professionals in descending order, by country. In terms of means, the countries Peru, Chile, Brazil and Argentina have the most experienced evaluators, with means for time since graduation greater than or equal to 13 years, while Paraguay, Uruguay, Bolivia, and Guatemala present professionals with mean time since graduation less than or equal to 5 years.

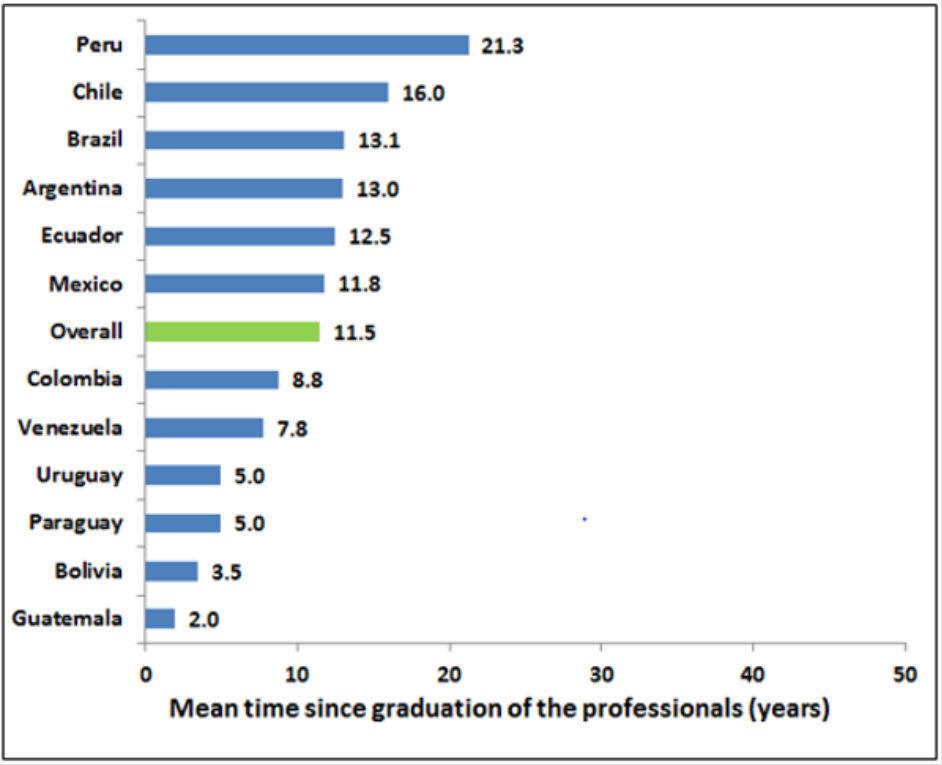

Figure 2: Mean time since graduation of the professionals in crescent order, by country. 


\begin{tabular}{|c|c|c|c|c|c|c|c|c|c|c|c|c|c|c|}
\hline \multirow{3}{*}{$\begin{array}{l}\overline{\bar{\pi}} \\
\frac{\pi}{0} \\
\delta\end{array}$} & 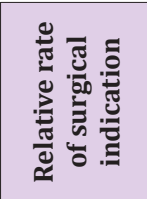 & $\begin{array}{l}\stackrel{\circ}{0} \\
\text { @ं } \\
\stackrel{0}{1}\end{array}$ & $\begin{array}{l}\stackrel{0}{\circ} \\
\stackrel{\infty}{+}\end{array}$ & $\begin{array}{l}\stackrel{0}{0} \\
\text { mे } \\
\text { in }\end{array}$ & $\begin{array}{l}\text { oे } \\
\text { in } \\
\text { i़ }\end{array}$ & $\begin{array}{l}\stackrel{0}{0} \\
\stackrel{0}{0} \\
0\end{array}$ & 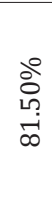 & $\begin{array}{l}\stackrel{े}{\circ} \\
\text { ᄋे } \\
\text { N }\end{array}$ & 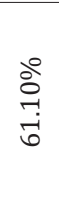 & $\begin{array}{l}0 \\
\text { oे } \\
\hat{0}\end{array}$ & $\begin{array}{l}\stackrel{0}{0} \\
\infty \\
\stackrel{+}{N}\end{array}$ & 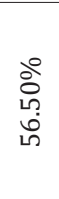 & $\begin{array}{l}\stackrel{\circ}{0} \\
\stackrel{े}{+}\end{array}$ & 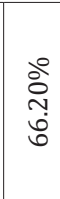 \\
\hline & 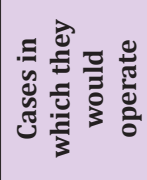 & 강 & $\stackrel{\stackrel{L}{2}}{\stackrel{2}{r}}$ & $\underset{\sim}{\stackrel{\sim}{\sim}}$ & $\stackrel{\circ}{\circ}$ & ڤ̆ & $\stackrel{0}{\stackrel{0}{二}}$ & $\stackrel{\text { N }}{ }$ & $\underset{\sim}{\mathbb{N}}$ & $\stackrel{\vec{N}}{ }$ & $\underset{\sim}{\tilde{m}}$ & $\vec{b}$ & : & $\begin{array}{l}\text { ర్ } \\
\text { ర్ }\end{array}$ \\
\hline & 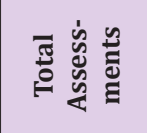 & 芯 & $\stackrel{\bullet}{\sim}$ & $\underset{\sim}{\stackrel{O}{J}}$ & $\underset{\sim}{\mathbb{N}}$ & N & $\stackrel{0}{\sim}$ & $\stackrel{\infty}{\stackrel{\infty}{\sim}}$ & 곡 & $\underset{\sim}{\stackrel{N}{N}}$ & $\underset{\widetilde{F}}{\mathscr{\gamma}}$ & $\stackrel{\infty}{\stackrel{\infty}{\sim}}$ & 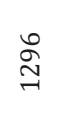 & ปี \\
\hline \multirow{3}{*}{ 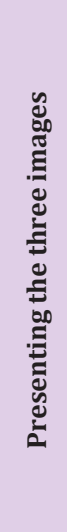 } & 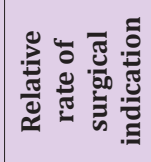 & $\begin{array}{l}\stackrel{0}{0} \\
\infty \\
\stackrel{0}{0}\end{array}$ & $\begin{array}{l}\stackrel{\circ}{0} \\
\text { مें }\end{array}$ & $\begin{array}{l}\stackrel{0}{0} \\
\text { in } \\
\infty \\
0 \\
0\end{array}$ & 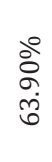 & $\begin{array}{l}\stackrel{0}{0} \\
\infty \\
+ \\
\dot{+}\end{array}$ & $\begin{array}{l}\text { ஓे } \\
\stackrel{0}{0} \\
\stackrel{1}{1}\end{array}$ & $\begin{array}{l}\stackrel{0}{0} \\
\stackrel{1}{0} \\
\text { m }\end{array}$ & 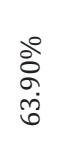 & $\begin{array}{l}\stackrel{0}{0} \\
\text { +े } \\
\stackrel{0}{1}\end{array}$ & 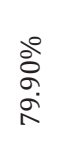 & $\begin{array}{l}\stackrel{0}{0} \\
\stackrel{0}{0}\end{array}$ & 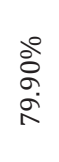 & 送 \\
\hline & 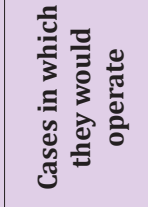 & $\underset{\sim}{\stackrel{N}{*}}$ & in & 옷 & gి & $\stackrel{\stackrel{\sim}{N}}{ }$ & ถิก & $\stackrel{m}{\rightarrow}$ & $\underset{\sim}{\widetilde{N}}$ & $\stackrel{゚}{\gtrless}$ & $\stackrel{\llcorner\Omega}{\exists}$ & $\stackrel{\sim}{N}$ & $\stackrel{\text { 용 }}{\text { r }}$ & N \\
\hline & 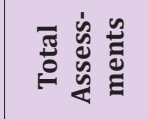 & $\stackrel{\infty}{\infty}$ & $\stackrel{N}{N}$ & $\begin{array}{l}\stackrel{0}{0} \\
\stackrel{0}{\sim}\end{array}$ & $\stackrel{\infty}{\stackrel{-}{\sim}}$ & $\underset{\sim}{\stackrel{N}{N}}$ & $\stackrel{N}{N}$ & $\stackrel{p}{m}$ & 芒 & $\stackrel{\infty}{\stackrel{\infty}{\sim}}$ & $\underset{\sim}{\stackrel{J}{*}}$ & $\stackrel{0}{m}$ & $\stackrel{\widetilde{F}}{\%}$ & $\underset{N}{\stackrel{N}{ }}$ \\
\hline \multirow{3}{*}{ 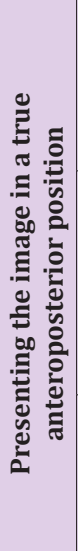 } & 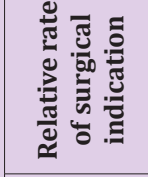 & 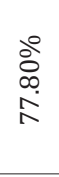 & $\begin{array}{l}\stackrel{0}{0} \\
\stackrel{\infty}{1} \\
\stackrel{1}{1}\end{array}$ & $\begin{array}{l}\text { هें } \\
\text { فे }\end{array}$ & $\begin{array}{l}\text { oे } \\
\stackrel{0}{0} \\
0\end{array}$ & $\begin{array}{l}\text { ठें } \\
\text { đે }\end{array}$ & 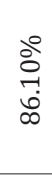 & $\begin{array}{l}\text { के } \\
\text { ఫे } \\
\text { ने }\end{array}$ & 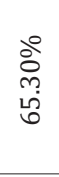 & 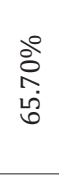 & $\begin{array}{l}\text { oे } \\
\text { : } \\
\text { ì }\end{array}$ & 仓ั & $\begin{array}{l}\text { @े } \\
\text { o. } \\
\text { م. }\end{array}$ & $\begin{array}{l}\text { |े } \\
\text { †े } \\
0 \\
0\end{array}$ \\
\hline & 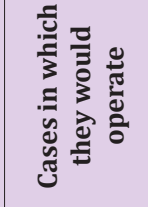 & $\stackrel{+}{N}$ & ட゚ & $\stackrel{m}{ }$ & $\approx$ & 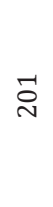 & $\widetilde{\sigma}$ & $n$ & 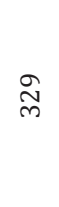 & $\Sigma$ & $\stackrel{\circ}{\stackrel{\circ}{\circ}}$ & $\hat{A}$ & 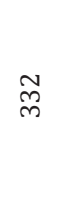 & 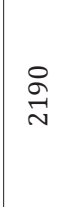 \\
\hline & 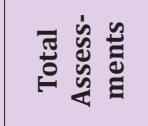 & $\stackrel{\infty}{\infty}$ & $\stackrel{N}{ }$ & $\begin{array}{l}\stackrel{\infty}{0} \\
\stackrel{\sim}{\sim}\end{array}$ & $\stackrel{\infty}{\sim}$ & $\underset{\sim}{\mathbb{N}}$ & $\stackrel{N}{ }$ & $\stackrel{m}{m}$ & 芒 & $\stackrel{\infty}{\stackrel{\infty}{\sim}}$ & $\underset{\sim}{\stackrel{\forall}{*}}$ & $\stackrel{p}{m}$ & $\widetilde{\mathscr{F}}$ & 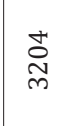 \\
\hline \multirow{3}{*}{ 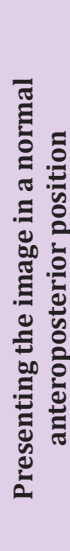 } & 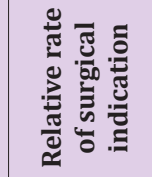 & $\begin{array}{l}\stackrel{े}{0} \\
\text { ָુ }\end{array}$ & $\begin{array}{l}D^{\circ} \\
\infty \\
\infty \\
\infty \\
\llcorner\end{array}$ & $\frac{\stackrel{0}{0}}{\stackrel{+}{0}}$ & $\begin{array}{l}\text { ఏे } \\
\text { ఏें } \\
\text { ம் }\end{array}$ & 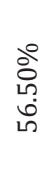 & $\begin{array}{l}\text { oे } \\
\stackrel{0}{0} \\
\stackrel{1}{1}\end{array}$ & $\begin{array}{l}\stackrel{\circ}{0} \\
\text { ஸें }\end{array}$ & 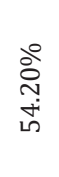 & $\begin{array}{l}\stackrel{0}{0} \\
\hat{0} \\
0\end{array}$ & $\begin{array}{l}\stackrel{0}{0} \\
\infty \\
\vdots \\
\stackrel{0}{1}\end{array}$ & $\begin{array}{l}\text { oे } \\
\text { o } \\
\text { م⿱ }\end{array}$ & 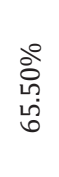 & $\begin{array}{l}0 \\
0 \\
0 \\
0\end{array}$ \\
\hline & 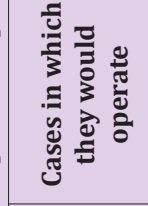 & $\stackrel{\infty}{\sim}$ & $\mathcal{F}$ & ?్ֶర & 녹 & $\stackrel{\substack{\infty \\
\sim}}{-\infty}$ & ถิ & $\sigma$ & $\stackrel{M}{\stackrel{M}{N}}$ & 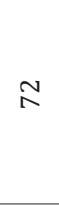 & 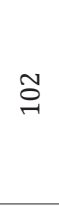 & $\stackrel{\text { N }}{ }$ & 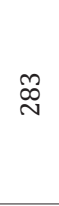 & $\begin{array}{l}\vec{\sigma} \\
\text { J }\end{array}$ \\
\hline & 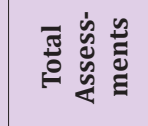 & $\begin{array}{l}\infty \\
\stackrel{\infty}{N}\end{array}$ & 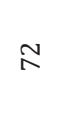 & $\begin{array}{l}\infty \\
\stackrel{\sim}{\infty}\end{array}$ & $\stackrel{\infty}{\stackrel{-}{\sim}}$ & $\underset{\sim}{\mathbb{N}}$ & $N$ & $\stackrel{m}{m}$ & 官 & $\stackrel{\infty}{\stackrel{\infty}{\sim}}$ & $\underset{\leftarrow}{\stackrel{+}{*}}$ & $\stackrel{m}{m}$ & $\underset{\widetilde{N}}{\sim}$ & స్心 \\
\hline & 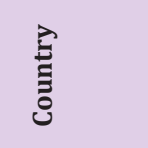 & 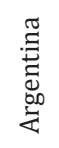 & $\begin{array}{l}\sum_{0}^{\frac{\pi}{2}} \\
\text { D. }\end{array}$ & 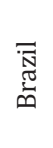 & 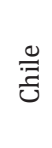 & 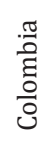 & 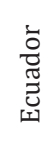 & 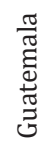 & 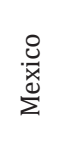 & 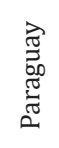 & $\begin{array}{l}\vec{J} \\
\Omega\end{array}$ & 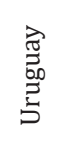 & 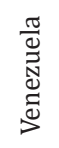 & 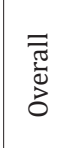 \\
\hline
\end{tabular}




\section{Decisions of the Professionals}

Table 3 shows the frequency distribution of the professionals' indications for surgery in the cases evaluated and the relative rate of surgical indication, by country, type of image presented, and overall. Figure 3 shows, for each type of image presented, and overall, the frequencies and the relative rates of surgical indications, by country and overall. For the professionals from Ecuador, Argentina, Mexico, and Chile, indications for surgery are more frequent when the images in a true anteroposterior position are presented. For the professionals from Peru, Venezuela, Bolivia, Paraguay, Brazil, Colombia, Uruguay, and Guatemala, as well as overall, indications for surgery are more frequent when the three images combined are presented. For all of the countries and overall, there is a lower frequency of indications for surgery when only the image in a normal anteroposterior position is presented.

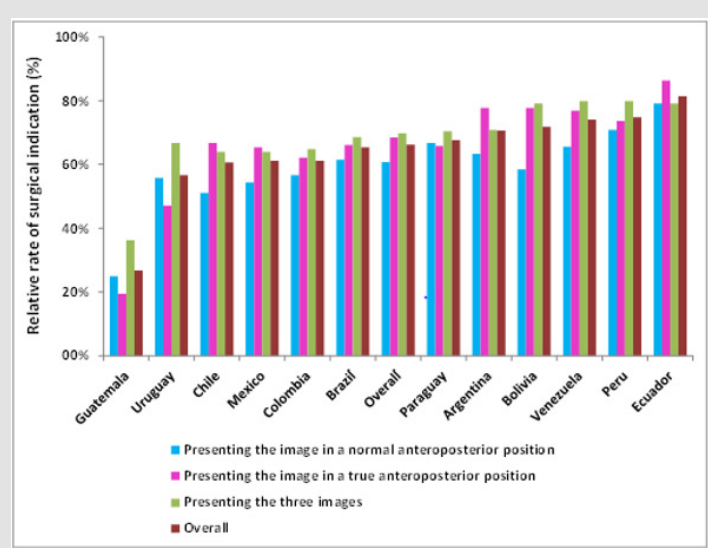

Figure 3: Relative Rates of Surgical Indication, by country, by type of image presented, and overall.

Table 3: Analysis of correlation between the number of surgical indications of the evaluators and their age and time since graduation.

\begin{tabular}{|c|c|c|}
\hline $\begin{array}{l}\text { Correlation coefficient between table row and column variables } \\
\text { (significance p-value of the correlation coefficient) }\end{array}$ & Evaluator age & Evaluator Time since Gradua-tion \\
\hline $\begin{array}{l}\text { Total evaluator surgical indications for the presentation in the lateral and the } \\
\text { normal anteroposterior view }\end{array}$ & $\begin{array}{r}0.06 \\
-0.559\end{array}$ & $\begin{array}{l}0.09 \\
-0.4\end{array}$ \\
\hline $\begin{array}{l}\text { Total evaluator surgical indications for the presentation in the lateral and the } \\
\text { true anteroposterior view }\end{array}$ & $\begin{array}{r}0.06 \\
-0.534\end{array}$ & $\begin{array}{r}0.12 \\
-0.246\end{array}$ \\
\hline Total evaluator surgical indications when the three images are presented. & $\begin{array}{r}0.07 \\
-0.534\end{array}$ & $\begin{array}{r}0.09 \\
-0.427\end{array}$ \\
\hline Total evaluator surgical indications & $\begin{array}{c}0.06 \\
-0.563\end{array}$ & $\begin{array}{r}0.11 \\
-0.32\end{array}$ \\
\hline
\end{tabular}

From analysis of the ranking of the relative rates of surgical indication provided in Table 3, it could be seen that the countries with higher relative rates of surgical indication are Ecuador, Peru, Venezuela, Bolivia, Argentina, and Paraguay, which have rates higher than the overall rates. The countries with lower relative rates of surgical indication are Guatemala, Uruguay, Mexico, Chile, Colombia and Brazil, which have rates lower than the overall rates of surgical indication. To determine whether the professional's decision to operate is associated with the professional's age and time since graduation, for each assessment the distributions of age and time since graduation of the professionals who did not indicate surgery and those who did indicate surgery were compared. Since the variables age and time since graduation did not follow a normal distribution ( $p$-value of the Shapiro-Wilk test less than 0.001 for both variables), the distributions were compared using the nonparametric Mann-Whitney test.

In only two of the 108 assessments (1.9\% of the assessments) was there a significant association of the decision to operate in relation to the age of the evaluating physician, that is, a p-value of less than $5 \%$ was found when comparing the distribution of the age of those who decided to operate with the distribution of the age of those who did not decide to operate. In both cases, the doctors who decided on surgical treatment were significantly older than the doctors who decided on conservative treatment. In the other assessments and overall, there was no significant association of the decision to operate with the age of the evaluating physician ( $p$-values greater than 5\% from the Mann-Whitney test comparing the distribution of the age of those who decided to operate with the distribution of the age who did not decide to operate). As the association of the decision to operate with the age of the evaluating physician occurred in a non-relevant frequency of cases, in only $1.9 \%$ of the assessments, it is concluded that the decision to operate is not significantly associated with the age of the evaluating physician.

In only five of the 108 assessments (4.6\% of the assessments) was there a significant association between the decision to operate and the time since the medical examiner graduated, that is, a $p$-value of less than $5 \%$ was found in the comparison of the distribution of the time since graduating for those who decided to operate with the distribution of the time since graduating of those who did not decide to operate. In these five cases, the doctors who decided on surgical treatment were significantly more experienced than the doctors who decided on conservative treatment. In the other assessments and overall, there was no significant association 
between the decision to operate and the time since graduation of the evaluating physician ( $p$-values greater than $5 \%$ from the MannWhitney test comparing the time since graduation of the evaluators who would not operate with the time since graduation of the evaluators who would operate).

As the association of the decision to operate with the time since graduation of the evaluating physician occurred in a nonrelevant frequency of cases ( $4.6 \%$ of assessments), it is concluded that the decision to operate is not significantly associated with the time since graduation of the evaluating physician. Additionally, we investigated whether the total number of the professional's surgical indications, in the three presentations and overall, is correlated with the professional's age and time since graduation. Due to the non-normality of the variables' distributions, the correlation was evaluated using Spearman's rank-order correlation coefficient. The correlations presented in Table 3 are small and not significantly different from zero (significance $p$-values greater than $5 \%$ ). It is concluded that the total number of surgical indications of the professional, in the three presentations and overall, is not correlated with the professional's age and time since graduation.

\section{Discussion}

This study demonstrated that, even in different medical scenarios (different countries), most evaluators opted for the use of three images of ankle fractures to indicate the use of surgical treatment. However, the true anteroposterior and lateral image, when compared with the three images combined, also provides more information such as: the type of fracture, classification, and surgical treatment. The treatment of ankle fractures involves diagnosis, classification, and treatment, and normally, three radiographic images are requested: anteroposterior, mortise, and lateral. In emergency departments, more than $12 \%$ of ankle x-rays are requested to assess ankle fractures [2-13] reported that $50 \%$ of ankle x-rays were not necessary and various studies have shown that they are excessive $[3,14,15]$.

According to the literature, various studies have shown how many images would be necessary to diagnose ankle fractures $[1,4,9,10,16]$. Cockshott et al. [2] observed that the fracture was present in only $29 \%$ of the x-rayed patients, Auletta et al. [13] in $30 \%$ of the patient $x$-rays, and Brandser et al. [11] found a $28 \%$ prevalence of fractures. Some investigators have observed that series with two images can replace the series of three images without decreasing the diagnosis of ankle fractures. Cockshott et al. [2] in a review with 242 ankle radiographs, observed that the anteroposterior and lateral image detected all the fractures and that the mortise image did not add information. On analyzing 945 ankle radiographs, Wallis 9 found 128 fractures (13.5\%). This author studied anteroposterior and lateral radiographs and compared them with mortise radiographs and, although $4.7 \%$ of the cases had fractures which in the anteroposterior radiograph had not been detected, he determined that the mortise image would not be necessary because the undiagnosed fractures were avulsion of the fibula and, therefore, would not alter the treatment established.

Vangsnesset [4] examined 123 cases of ankle fractures and compared the detection of fracture using the mortise and lateral image with the three images. They observed 95\% "accuracy" with this combination and reported that the choice of the mortise and lateral image over the anteroposterior and lateral image was the authors' decision to carry out the study. Brage et al. [10] studied the intra- and inter-observer agreement for the classification of 99 ankle fractures using two and three images and found that the agreement was better with two images. They recommended the use of a mortise and lateral image for the classification of ankle fractures. However, they did not focus on the diagnosis of the fracture. Brandser et al. [11] observed that the combination of both images (anteroposterior and mortise) was similar for diagnosing fractures and did not find a reason for choosing one over the other. However, they analyzed only the fracture diagnosis and did not study whether the three images were necessary to classify the fractures or decide on treatment. This study showed that, overall, surgeons indicate surgery more frequently when three images are available (69.7\% surgical indication when three images are available).

However, this is not the pattern for the groups of surgeons in all countries, since when looking at the rates of surgical indication for each country separately, there are some differences. When comparing the rates of surgical indication from the images in anteroposterior, lateral, and in mortise, it was observed that, in general, the rate of surgical indication is higher when the image in true anteroposterior position is shown (68.4\% versus $60.6 \%$ when the normal anteroposterior position is shown). It is worth repeating that this study focused on the surgical indication between the images, not studying the classification or diagnosis. For the first time in the literature, doctors from 12 different countries participated in assessments regarding the images of ankle fractures, which made it possible to identify and warn that there are differences between the rates of surgical indication in different countries. For the evaluators from Ecuador, Argentina, Mexico, and Chile, indications for surgery are more frequent when the images are presented in true anteroposterior position.

For the professionals from Peru, Venezuela, Bolivia, Paraguay, Brazil, Colombia, Uruguay, and Guatemala, as well as overall, indications for surgery are more frequent when images of the three positions are presented. In all of the countries and overall, it appears that the lowest frequencies of surgical indications are presented when the image is in normal anteroposterior position. The variety of patterns from different countries proves the need to provide as many images as possible. This study also identified that the decision to operate is not significantly associated with the age and experience of the surgeon. The total number of surgical indications by the professional, in the three presentations and overall, is also not correlated with the age and experience of the professional. 


\section{Conclusion}

In most of the countries, indications for surgery are more frequent when images of the three positions are presented. However, the highest frequencies of surgery indications were observed when only the image in a true anteroposterior and lateral position were presented. Surgical indications are not associated with the surgeon's time since graduation.

\section{References}

1. Court Brown CM, Caesar B (2006) Epidemiology of adult fractures: a review. Injury 37(8): 691-697.

2. Cockshott WP, Jenkin JK, Pui M (1983) Limiting the use of routine radiography for acute ankle injuries. Can Med Assoc J 129(2): 129-131.

3. Stiell IG, Greenberg GH, McKnight RD, JP Stewart, J Maloney, et al. (1993) Decision rules for the use of radiography in acute ankle injuries: refinement and prospective validation. JAMA 269(9): 1127-1132.

4. Vangsness CT, Carter V, Hunt T (1994) Radiographic diagnosis of ankle fractures: are three views necessary? Foot Ankle Int 15(4): 172-174.

5. Brand DA, Frazier WH, Kohlhepp WC (1982) A protocol for selecting patients with injured extremities who need x-rays. N Engl J Med 306: 333-339.

6. Stiell IG, McKnight RD, Greenberg GH, C Johns, J R Worthington, et al. (1994) Implementation of the Ottawa ankle rules. JAMA 271(11): 827832.

ISSN: 2574-1241

DOI: $10.26717 / B J S T R .2021 .34 .005484$

Amorim Luiz Eduardo. Biomed J Sci \& Tech Res

(C) (i) This work is licensed under Creative

Submission Link: https://biomedres.us/submit-manuscript.php
7. Stiell IG, McKnight RD, Greenberg GH (1992) Interobserver agreement in the examination of acute ankle injury patients. Am J Emer Med 10(1): $14-17$

8. Stiell IG, McDowell I, Nair RC, G Greenberg, RD McKnight, et al. (1992) Use of radiography in acute ankle injuries: physicians' attitudes and practice. Can Med Assoc J 147(11): 1671-1678.

9. Wallis MG (1989) Are three views necessary to examine acute ankle injuries? Clin Radiol 40(4): 424-425.

10. Brage ME, Rockett M, Vraney R (1998) Ankle fracture classification: a comparison of reliability of three X-ray views versus two. Foot Ankle Int 19(8): 555-562.

11. Brandser EA, Berbaum KS, Dorfman DD, CL Saltzman, JL Marsh, et al. (2000) Contribution of Individual Projections Alone and in Combination for Radiographic Detection of Ankle Fractures. AJR 174(6): 1691-1697.

12. Brooks SC, Potter BT, Rainey JB (1981) Inversion injuries of the ankle: clinical assessment and radiographic review. Br Med J 282(6264): 607608.

13. Auletta AG, Conway WF, Hayes CW (1991) Indications for radiography in patients with acute ankle injuries: role of the physical examination. AJR 157: 789-791.

14. Hall FM (1976) Overutilization of radiological examinations. Radiology 120: $443-448$.

15. Abrams HL (1979) The overutilization of x-rays. N Engl J Med 300: 12131216.

16. De Smet AA, Doherty MP, Norris MA (1999) Are oblique views needed for trauma radiography of the distal extremities? AJR 172: 1561-1565.

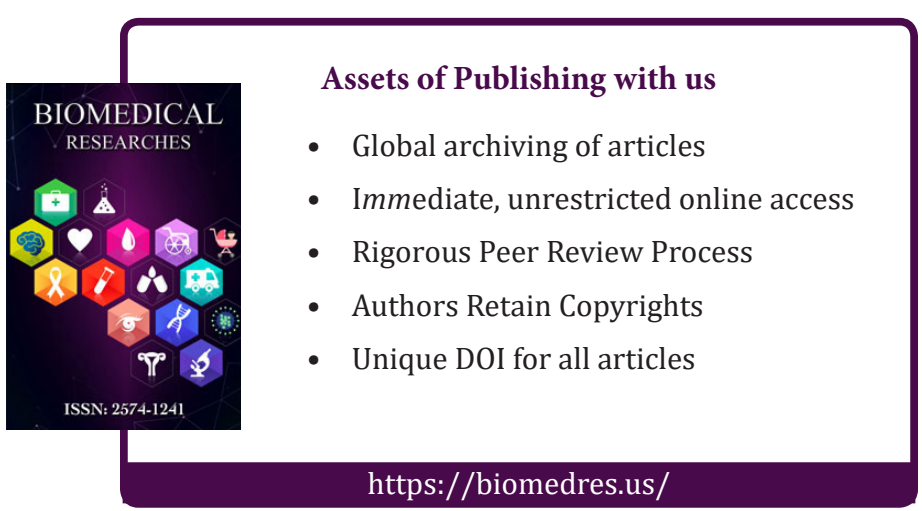

